\title{
Electrospray Ionization-Ion Trap Mass Spectrometry Study of PQAAPro and PQProAA Mimetic Derivatives of the Antimalarial Primaquine
}

\author{
Nuno Vale, ${ }^{\text {a }}$ Joana Matos, ${ }^{\text {a }}$ Rui Moreira, ${ }^{\mathbf{b}}$ and Paula Gomes ${ }^{\mathbf{a}}$ \\ ${ }^{a}$ CIQUP, Chemistry Department, Faculty of Sciences, University of Porto, Porto, Portugal \\ $\mathrm{b}$ iMed.UL, Institute for Medicines and Pharmaceutical Sciences, Faculty of Pharmacy, University of Lisbon, \\ Lisbon, Portugal
}

Electrospray ionization-ion trap mass spectrometry (ESI-MS) of imidazolidin-4-one peptidomimetic derivatives of the antimalarial drug primaquine $(\mathrm{PQ})$ is reported. These compounds contain the imidazolidin-4-one moiety either at the $N$ - or the C-terminal of a dipeptide backbone, thus respectively mimicking PQ-Amino Acid-Proline (PQAAPro) and PQProAA derivatives of $\mathrm{PQ}$. Both the peptidomimetics and precursors previously developed by us are promising drug candidates, as they were found to be active against rodent Plasmodium berghei malaria and Pneumocystis carinii pneumonia. Collision-induced dissociation (CID) and tandemmass spectra (MS) of the title compounds, and fragmentation pathways thereof, led to the following findings: (1) CID patterns present some parallelism with the reactivity towards hydrolysis previously found for the same or related compounds; (2) a positional shift of the imidazolidin-4-one ring is reflected on both degree and pathways of fragmentation, which makes tandem-MS a key tool for differentiation of imidazolidin-4-one isomers; (3) the major MS/MS fragmentation of PQProAA mimetics involves release of a neutral diketopiperazine (DKP), in parallel to the "diketopiperazine pathway" described in tandem-MS studies of oligopeptides; (4) the relative abundance of a major fragment in tandem-MS spectra is inversely correlated with the size of the $N$-terminal AA in PQProAA mimetics. Overall, this work embodies an original and valuable contribution towards a deeper insight into the molecular properties of novel antimalarials, which can be viewed as representative of both the 8-aminoquinoline and, especially, the imidazolidin-4-one structural classes. (J Am Soc Mass Spectrom 2008, 19, 1476-1490) (C) 2008 American Society for Mass Spectrometry

$\mathrm{O}$ ver the past decade, electrospray ionization mass spectrometry (ESI-MS) has been used for the most diverse analytical purposes. This technique has provided deeper insight into the structural properties and stability of numerous compounds, from natural products [1-3] to synthetic drugs [4-8], peptides [9-23], and heterocycles [24-28], among many others. Notwithstanding, little has been done on the application of this technique to the study of relevant antimalarials such as primaquine $(P Q, 1)$ or related structures. Analytical methods focused on PQ or its analogues have been so far applied to pharmacokinetics studies and metabolite scrutiny [29-37] or isomer characterization [38, 39]. Examples of mass spectrometry techniques employed to the study/analysis of $P Q$ and related compounds include fast atom bombardment mass spectral (FAB-MS) analysis of PQ oxidation products [32] and supercritical fluid chromatography-mass

Address reprint requests to Dr. P. Gomes, Centro de Investigação em Química da Universidade do Porto, Departamento de Química, Faculdade de Ciências, Universidade do Porto, R. Campo Alegre 687, P-4169-007 Porto, Portugal. E-mail: pgomes@fc.up.pt spectrometry (SFC-MS) used to elucidate differences in the MS fragmentation patterns of PQ (free base), $P Q$ diphosphate and its positional isomer quinocide and to achieve good resolution between these three compounds in short analysis times [36]. Apart from very few exceptions, such as the identification of the 8-aminoquinoline (8-AQ) NPC 1161 and its metabolites in biological samples [37], or studies on antimalarial compounds reported by Nicolas et al. [5], Smyth et al. and $\mathrm{O}^{\prime}$ Donnell et al. [1, 2], ESI-MS ${ }^{n}$ techniques have seldom been employed to the characterization of antimalarial 8- $A Q$, and much less to $P Q$ or its analogues.

Our research group has been working on the development of PQ derivatives with antimalarial activity and increased oral bioavailability, obtained by $\mathrm{N}$-acylation of the parent drug with amino acids and further modification of the $N$-acyl derivatives (2) by insertion of an imidazolidin-4-one moiety (3) [40-45], which is commonly employed in the design of protease-resistant peptidomimetics [46-52].

Structures like 3 were found to be significantly active as gametocytocides in rodent $P$. berghei malaria [41] and 


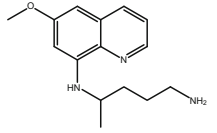

1

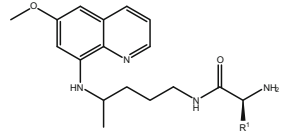

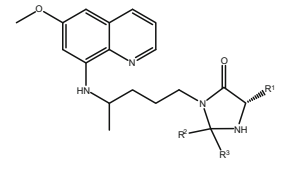

3 establishment of MS fragmentation patterns that can be used for reactivity predictions. To that purpose, we have carried out a thorough study of $\mathbf{5}$ and $\mathbf{6}$ by CID and tandem-MS analysis, whose results are herein reported and discussed.

\section{Experimental}

to display modest blood schizontocidal activity against a chloroquine-resistant strain of P. falciparum [44], the causative agent of the deadliest form of human malaria. They were also active against $P$. carinii, an opportunistic fungus that is responsible for pneumocystic pneumonia affecting immune-suppressed mammal hosts [44]. This bioactivity pattern reflects the therapeutic profile of $\mathrm{PQ}$ itself, but hydrolysis studies have shown imidazolidin4-ones 3 to be astonishingly stable, thus being active per se [40-42]. To get a better understanding of structural properties of compounds derived from 3, we have recently engaged in an ESI-MS study of a family of 20 such compounds [45]. Experiments by CID in the nozzleskimmer region (NSR) and by tandem-MS have shown imidazolidin-4-ones 3 to be remarkably stable, reflecting our observations in aqueous media despite the distinct degradation pathways [45]. We have now stepped forward to the synthesis and study of two new families of PQ imidazolidin-4-ones, 5 and $\mathbf{6}$, obtained from PQ.

$\mathrm{N}$-dipeptidyl derivatives (4) or by acylation of the imidazolidin-4-one's N-1 in 3, respectively (Scheme 1). These compounds were designed as mimetics of, respectively, PQAAPro and PQProAA peptide derivatives of primaquine, resistant to oxidative deamination $[53,54]$. Full characterization of 5 and $\mathbf{6}$ passes by the

\section{Chemistry}

Synthesis of compounds PQAAPro mimetics (5). The synthetic route to Structures $\mathbf{5}$ is depicted in Scheme 1a-e. Briefly, PQ was coupled to an $N^{\alpha}$-tert-butyloxycarbonylprotected L-amino acid (BocAA ${ }^{1} \mathrm{OH}$ ) through carbodiimide (di-isopropyl-, DIC, or dicyclohexyl-carbodiimide, DCCI)/1-hydroxybenzotriazole (HOBt)-mediated condensations in dichloromethane (DCM) and in the pres(Boc) group was then removed by acidolytic cleavage with trifluoroacetic acid (TFA), and the resulting trifluoroacetate was converted into the free base by neutralization with aqueous (aq) $\mathrm{Na}_{2} \mathrm{CO}_{3}$. A second amino acid residue $\left(\mathrm{BocAA}^{4} \mathrm{OH}\right)$ was coupled by similar procedures and, after Boc removal with TFA, followed by neutralization with aq $\mathrm{Na}_{2} \mathrm{CO}_{3}$ to release intermediates 4; these were reacted with ketones (propanone, cyclohexanone, 4-methylcyclohexanone, and cycloheptanone) to yield the target imidazolidin-4-one Structures 5. These were successfully characterized by either ESI-MS or matrix-assisted laser desorption-time-of-flight (MALDITOF) MS as well as by proton $\left({ }^{1} \mathrm{H}-\right)$ and carbon $\left({ }^{13} \mathrm{C}-\right)$ nuclear magnetic resonance (NMR), as reported elsewhere [53]. ence of triethylamine (TEA). The tert-butyloxycarbonyl

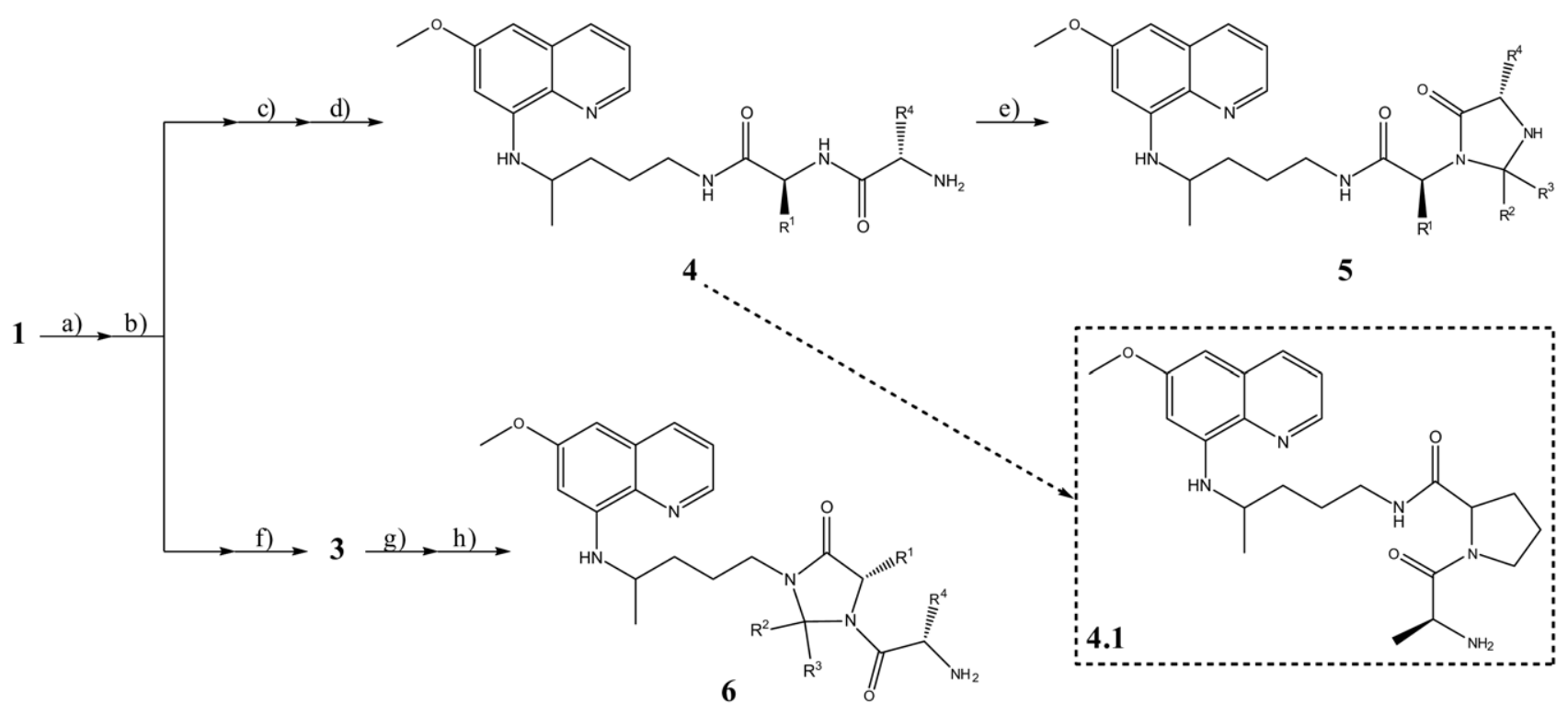

Scheme 1. Synthetic routes to Compounds 5 and 6 [40, 43, 53, 54]: (a) BocAA ${ }^{1} \mathrm{OH}, \mathrm{DCCI}$ or DIC, HOBt, TEA, DCM, $0{ }^{\circ} \mathrm{C}$ to r.t.; (b) neat TFA, aq. $30 \% \mathrm{Na}_{2} \mathrm{CO}_{3}$, r.t.; (c) BocAA ${ }^{4} \mathrm{OH}$, DCCI or DIC, HOBt, TEA, DCM, $0{ }^{\circ} \mathrm{C}$ to r.t.; (d) neat TFA or TFA $50 \%$ in DCM, aq. $30 \% \mathrm{Na}_{2} \mathrm{CO}_{3}$, r.t.; (e) $\mathrm{R}^{2}(\mathrm{C}=\mathrm{O}) \mathrm{R}^{3}$, TEA, $\mathrm{MeOH}$, reflux; (f) propanone $\left(\mathrm{R}^{2}=\mathrm{R}^{3}=\mathrm{Me}\right)$, TEA, $\mathrm{MeOH}$, reflux; (g) BocAA ${ }^{4} \mathrm{OH}, \mathrm{DIC}$, HOBt, TEA, DMF, $-10{ }^{\circ} \mathrm{C}$ to r.t., inert atmosphere; (h) TFA $30 \%$ in DCM, aq. $30 \% \mathrm{Na}_{2} \mathrm{CO}_{3}$. 
Synthesis of compounds PQProAA mimetics (6). Structures 6 were obtained by coupling an $N^{\alpha}$-Boc-protected L-amino acid (BocAA ${ }^{4} \mathrm{OH}$ ) to imidazolidin-4-ones 3, whose synthesis has been described elsewhere [40, 43], and is depicted on Scheme 1a, $\mathbf{b}$, and $\mathbf{f}$. Coupling of BocAA ${ }^{4} \mathrm{OH}$ to Compounds 3 was carried out also by means of a carbodiimide (DIC) as coupling agent and HOBt as the auxiliary nucleophile (Scheme 1g) in $\mathrm{N}, \mathrm{N}-$ dimethylformamide (DMF). After Boc removal with a solution of TFA in DCM followed by neutralization with aq $\mathrm{Na}_{2} \mathrm{CO}_{3}$, Compounds 6 were well obtained and characterized by MALDI-TOF or ESI-MS, ${ }^{1} \mathrm{H}-\mathrm{NMR}$ and ${ }^{13} \mathrm{C}-\mathrm{NMR}$, as recently reported [54].

Synthesis of PQProAla (4.1). As imidazolidizin-4-ones are often used as proline surrogates [55-57], we have also prepared the $N$-alanylprolyl derivative of $P Q$ (PQProAla, 4.1) through steps Scheme 1a-d, using $\mathrm{BocProOH}$ and BocAlaOH as, respectively, $\mathrm{BocAA}{ }^{1} \mathrm{OH}$ and $\mathrm{BocAA}^{4} \mathrm{OH}$ (spectroscopic data for compound 4.1 is provided in the Supporting Information file). This targeted the inclusion of 4.1 in the MS fragmentation studies of the title compounds, for comparison purposes.

\section{ESI-MS ${ }^{n}$ Analysis}

ESI-MS $^{n}$ studies on Compounds 1, 4.1, 5.1-5.15, and 6.1-6.9 (Table 1) were achieved using a Finnigan Surveyor LCQ DECA XP MAX quadrupole ion trap mass spectrometer, utilizing electrospray ionization. Methanolic solutions of the compounds containing $0.1 \%$ acetic acid were infused into the ESI probe at a rate of $3 \mu \mathrm{L} / \mathrm{min}$. All other details of the experimental setup in the MS studies were as recently described [45], with the exception that the Vs CID parameter varied between 10 and $100 \mathrm{~V}$ in fragmentation studies on the NSR. The relevance of the experimental procedures adopted in our MS studies have been recently explained in our previous work concerning compounds derived from 3 [45].

All ESI-MS ${ }^{n}$ spectra obtained are supplied in the Supporting Information file, which can be found in the electronic version of this article.

\section{Results and Discussion}

\section{Experiments in the Nozzle-Skimmer Region}

Compounds from both families, $\mathbf{5}$ and $\mathbf{6}$, were analyzed in the NSR at CID potentials of 10, 25, 50, 75, and $100 \mathrm{~V}$

Table 1. PQ (1) and derivatives (4, 5, and 6) covered by the present study, and average $\mathrm{m} / \mathrm{z}$ values for the main species detected in their corresponding full-MS spectra

\begin{tabular}{|c|c|c|c|c|c|c|c|}
\hline Compound & $\mathrm{R}^{1}$ & $\mathrm{R}^{2}$ & $\mathrm{R}^{3}$ & $\mathrm{R}^{4}$ & $\mathrm{MW} / \mathrm{g} \mathrm{mol}^{-1}$ & $m / z[\mathrm{M}+\mathrm{H}]^{+}$ & $m / z[\mathrm{M}+\mathrm{Na}]^{+}$ \\
\hline 5.1 & $\mathrm{H}$ & & & $\mathrm{H}$ & 413.24 & 414.80 & 437.33 \\
\hline 5.2 & $\mathrm{H}$ & & & $\mathrm{Me}$ & 427.26 & 428.93 & 450.80 \\
\hline 5.3 & $\mathrm{Me}$ & $\mathrm{Me}$ & $\mathrm{Me}$ & $\mathrm{H}$ & 427.26 & 428.87 & 450.87 \\
\hline 5.4 & $\mathrm{Me}$ & & & $\mathrm{Me}$ & 441.27 & 442.80 & 465.27 \\
\hline 5.5 & $\mathrm{Me}$ & & & $\left(\mathrm{CH}_{2}\right)_{2} \mathrm{SMe}$ & 501.28 & 502.20 & 525.07 \\
\hline 5.6 & $\mathrm{H}$ & & & $\mathrm{Bzl}$ & 503.29 & 504.87 & 526.87 \\
\hline 5.7 & $\mathrm{H}$ & & & $\mathrm{Bzl}$ & 543.32 & 544.87 & 566.73 \\
\hline 5.8 & $\mathrm{H}$ & & & $\mathrm{CH}_{3}$ & 467.29 & 468.93 & 490.93 \\
\hline 5.9 & $\mathrm{Me}$ & & & $\mathrm{H}^{\circ}$ & 467.29 & 468.73 & 491.00 \\
\hline 5.10 & $\mathrm{Me}$ & & & $\mathrm{Me}$ & 481.31 & 482.93 & 504.80 \\
\hline 5.11 & $\mathrm{Me}$ & & & $\left(\mathrm{CH}_{2}\right)_{2} \mathrm{SMe}$ & 541.31 & 542.87 & 564.80 \\
\hline 5.12 & ${ }^{i} \mathrm{Bu}$ & & & $\mathrm{H}$ & 509.34 & 510.80 & 533.27 \\
\hline 5.13 & Bzl & & & $\mathrm{H}$ & 543.32 & 544.93 & 567.07 \\
\hline 5.14 & $\mathrm{H}$ & $\left(\mathrm{CH}_{2}\right)_{2}$ & $\left(\mathrm{CH}_{2}\right)_{2}$ & Bzl & 557.34 & 558.80 & 580.67 \\
\hline 5.15 & $\mathrm{H}$ & & & $\mathrm{Bzl}$ & 557.34 & 558.93 & 580.67 \\
\hline 6.1 & $\mathrm{H}$ & & & $\mathrm{H}$ & 413.24 & 414.87 & 436.87 \\
\hline 6.2 & $\mathrm{H}$ & & & $\mathrm{Me}$ & 427.26 & 428.98 & 451.07 \\
\hline 6.3 & $\mathrm{H}$ & & & ${ }^{i} \operatorname{Pr}$ & 455.29 & 456.93 & 478.73 \\
\hline 6.4 & $\mathrm{H}$ & & & ${ }^{i} \mathrm{Bu}$ & 469.31 & 470.47 & 492.67 \\
\hline 6.5 & $\mathrm{H}$ & $\mathrm{Me}$ & $\mathrm{Me}$ & $\mathrm{CH}(\mathrm{Me}) \mathrm{CH}_{2} \mathrm{Me}$ & 469.31 & 470.93 & 492.73 \\
\hline 6.6 & $\mathrm{H}$ & & & $\left(\mathrm{CH}_{2}\right)_{2} \mathrm{SMe}$ & 487.26 & 489.18 & 510.87 \\
\hline 6.7 & $\mathrm{H}$ & & & $\mathrm{Bzl}$ & 503.29 & 504.88 & 526.87 \\
\hline 6.8 & $\mathrm{Me}$ & & & $\mathrm{H}$ & 427.26 & 428.67 & 450.53 \\
\hline 6.9 & ${ }^{i} \mathrm{Bu}$ & & & $\mathrm{H}$ & 469.31 & 471.13 & 492.13 \\
\hline 1 & - & - & - & - & 259.17 & 260.72 & - \\
\hline 4.1 & $-\left(\mathrm{CH}_{2}\right)_{3}^{-}$ & - & - & $\mathrm{Me}$ & 427.26 & 428.93 & 450.80 \\
\hline
\end{tabular}



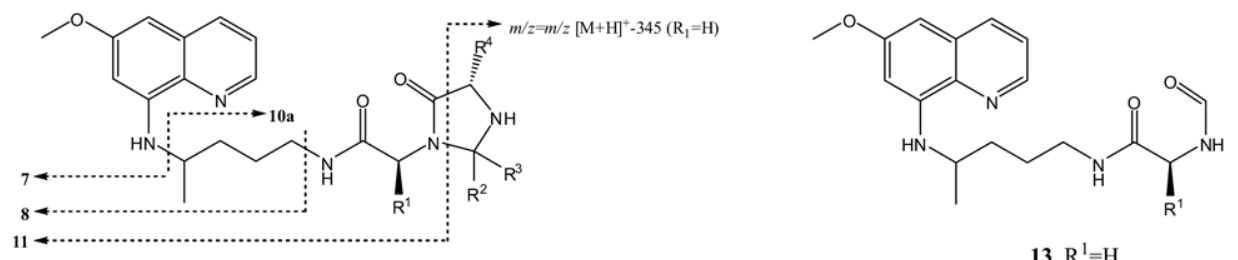
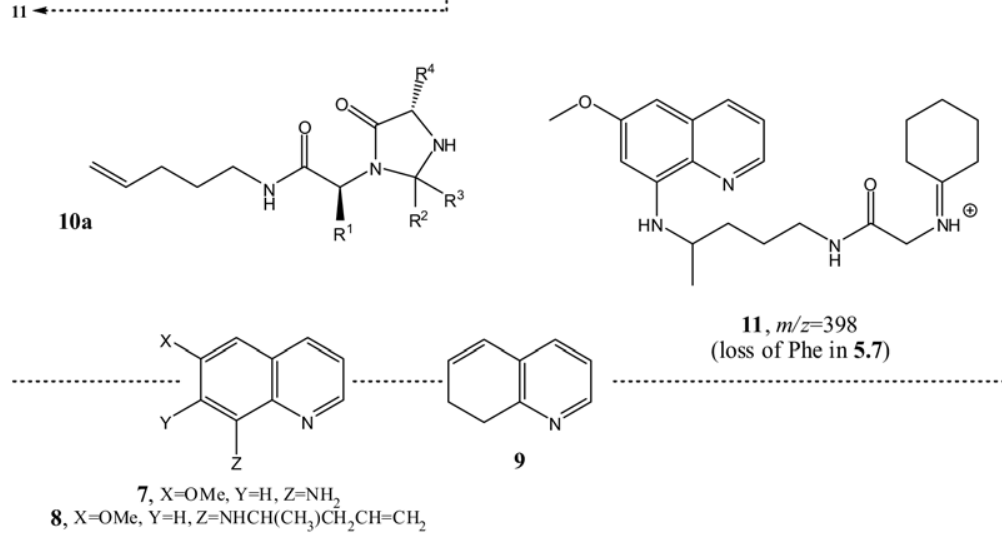

8, $\mathrm{X}=\mathrm{OMe}, \mathrm{Y}=\mathrm{H}, \mathrm{Z}=\mathrm{NHCH}\left(\mathrm{CH}_{3}\right) \mathrm{CH}_{2} \mathrm{CH}=\mathrm{CH}_{2}$
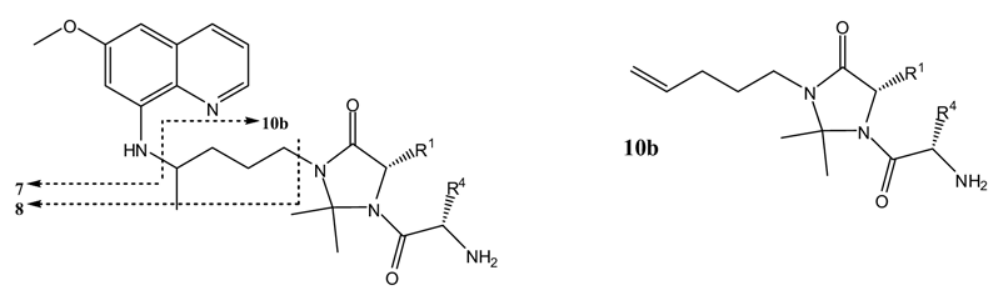

13, $\mathrm{R}^{1}=\mathrm{H}$

$\left(345 \mathrm{gmol}^{-1}\right)$

Scheme 2. Main fragmentations and associated fragments, observed for compounds derived from 5 (above the dashed line) and $\mathbf{6}$ (below the dashed line) in the course of ESI-MS analyses in the NSR (see text). Common fragments are displayed over the dashed line.

and a major finding from these analyses was that both types of structures were overall stable to fragmentation under these conditions and presented similar dissociation patterns, related to those previously observed for the precursor Structures 3 [45]. Generally, spectra from PQAAPro mimetics (5) contained fewer product ions than those from PQProAA mimetics (6).

Predominant species on the CID spectra of imidazolidin4-ones 5 were basically the quasi-molecular ions of the original compound, $[\mathrm{M}+\mathrm{H}]^{+}$, its sodium adduct, $[\mathrm{M}+$ $\mathrm{Na}]^{+}$, its dimer $\left[\mathrm{M}_{2}+\mathrm{H}\right]^{+}$, or the sodium adduct of the latter, $\left[\mathrm{M}_{2}+\mathrm{Na}\right]^{+}$. Nonetheless, fragmentation patterns could be clearly drawn, which consistently included peaks at $m / z 175,243,132$, and $\left([\mathrm{M}+\mathrm{H}]^{+}\right)-176$. These were respectively assigned to the quasimolecular ions ([M + $\mathrm{H}]^{+}$) of 6-methoxy-8-aminoquinoline (MAQ, 7 on Scheme 2), "desamino"-PQ (8 on Scheme 2, 6-methoxy- $N$-(pent4-en-2-yl)quinolin-8-amine), 7,8-dihydroquinoline (DHQ, 9 on Scheme 2) and the fragment of 5 obtained after loss of MAQ and dehydrogenation (10a in Scheme 2). Assignment of the peak at $m / z 132$ to DHQ was based on our previous work [45] as well as on the reported identification of this species as the major product of MS ${ }^{2}$ fragmentation of nicotine [1]. These and other relevant product ions are illustrated by the CID spectrum of 5.6, in Figure 1.
By comparing results for different $R^{1} / R^{4}$ pairs of amino acids, structure-reactivity correlations cannot be clearly obtained from CID experiments. The presence of one Gly at either position $\left(\mathrm{R}^{1}\right.$ or $\left.\mathrm{R}^{4}=\mathrm{H}\right)$, as in Compounds 5.2, 5.3, and 5.6, yields higher percentages of the above mentioned 8-AQ fragments (7, 8, and 9) than Compounds 5.4 and 5.5 where $R^{1}$ and $R^{4} \neq H$ (relevant spectra in Supporting Information). This could be interpreted as due to a higher sensitivity associated to Gly-bearing compounds, but 5.1 that contains two Gly residues $\left(R^{1}=R^{2}=H\right)$ presents a lower fragmentation degree while displaying strong association with sodium cations. Besides these specific examples of Gly-containing structures, all compounds of the subset 5.1-5.6 display virtually the same fragmentation pattern, irrespective of the nature or relative position of amino acids at both $R^{1}$ and $R^{4}$. The same occurred with their analogues derived from cycloketones (5.7 to 5.15), though spectra from this second subset tend to display fewer product ions than those from the first one (cf. relevant spectra in Supporting Information).

The particular case of 5.11, which bears a methionine residue, is also noteworthy, as oxidation of its thioether sulphur to a sulfone was observed. This is a current in vivo phenomenon for peptides and proteins, whose 

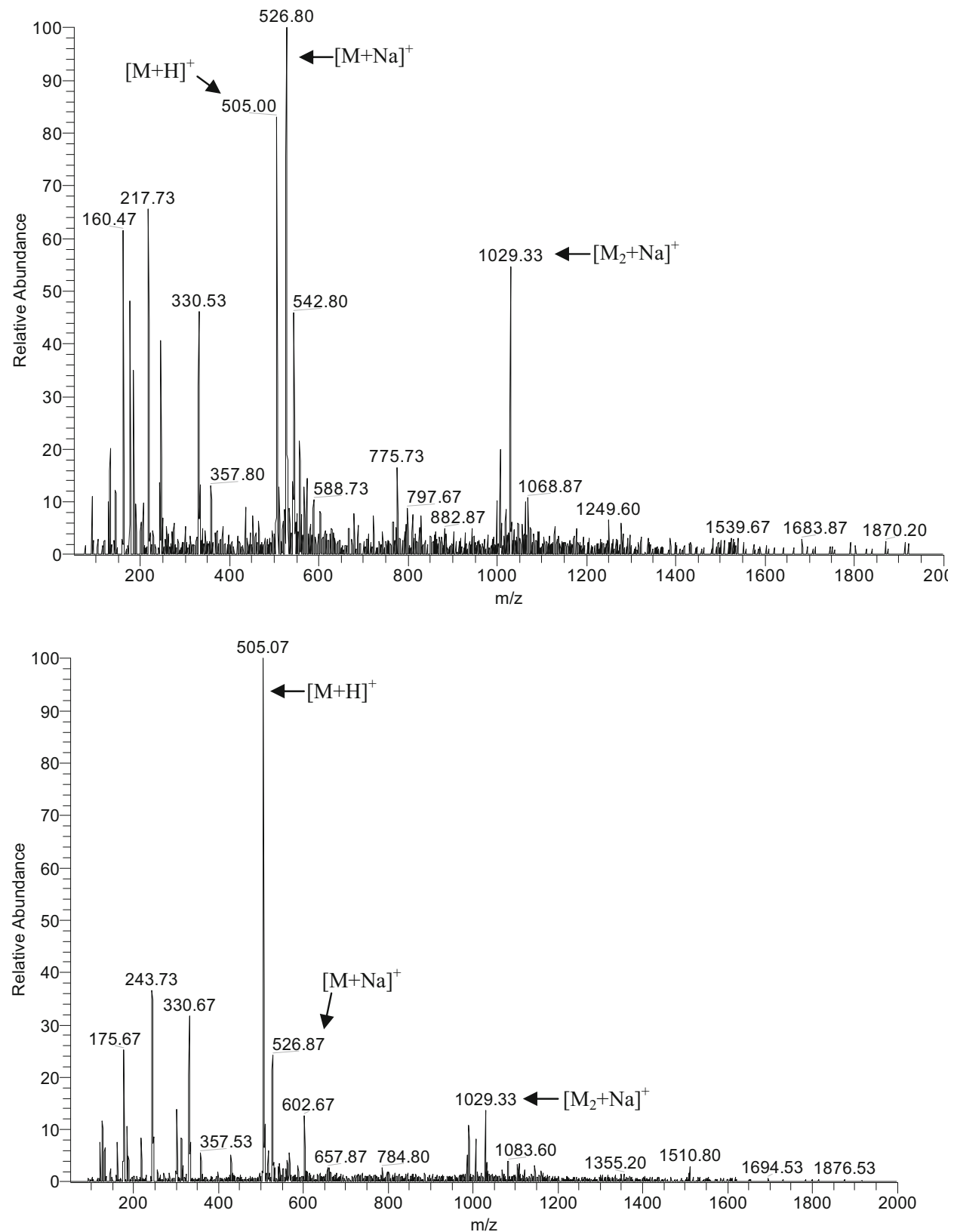

Figure 1. Fragmentation spectra for Compounds 5.6 (top) and 6.7 (bottom) on the NSR at 50 V.

Met residues easily undergo oxidation to methionine sulfone [58-61].

Other important peaks were observed in CID spectra at low collision energies, associated to imidazolidin-4one ring breaking. For instance, the CID spectra of 5.7 at 10 and $25 \mathrm{~V}$ (Supporting Information) display peaks at $\mathrm{m} / \mathrm{z} 398$ and at 371 that were, respectively, attributed to loss of the imidazolidin-4-one's amino acid building block (Phe) yielding 11 (Scheme 2), and to loss of $R^{2}, R^{3}$, and $\mathrm{R}^{4}$ to give 12 (Scheme 2). At higher collision energies, these species tended to disappear, due to their dissociation into smaller product ions such as 7-9, further contributing to the prominence of these ions in spectra acquired at CID $\geq 50 \mathrm{~V}$. Nevertheless, in our viewpoint the key fragmentation in Structures $\mathbf{5}$ was the loss of $345 \mathrm{Da}$, as it results from imidazolidin4-one ring-opening with concomitant release of $\mathrm{N}$ (formamidomethylcarbonyl)primaquine (13 in Scheme 2). In many cases, this was the most important fragmentation at CID $\geq 75 \mathrm{~V}$ (spectrum of $\mathbf{5 . 6}$ on the top of Figure 1), and was found to be a key feature for the structural distinction between isomeric Structures 5 and 6 , as only the first ones display imidazolidin-4one ring opening as a result of collision-induced dissociation (compare spectra of $\mathbf{5 . 6}$ and of its isomer 6.7 on Figure 1).

In fact, by comparing spectra obtained for Compound 5.6 and its isomer 6.7, two features are immediately eye-catching: (1) the spectrum of 6.7 present fewer product ions than that of 5.6, and (2) there is no 
evidence of imidazolidin-4-one ring opening for 6.7 . The distinct behavior of 6.7, compared with that of its isomer 5.6, was consistently observed for all compounds derived from 6 whose imidazolidin-4-one rings thus seem to be more stable towards fragmentation in the NSR region than those on their 5 analogues. In other words, shift of the imidazolidin-4-one ring from the $N$-terminus of the dipeptide backbone (i.e., as in 5) to the C-terminus (i.e., as in 6) leads to a significant decrease in the reactivity of the five-membered ring, observable at all voltages used (relevant spectra in Supporting Information). Thus, in general, main insource fragmentations of compounds derived from 6 are practically limited to loss of MAQ (7) and of "desamino"-PQ (8).

To sum up, the in-source fragmentation behavior is practically superimposable for all compounds belonging to the same family, i.e., to 5 or to $\mathbf{6}$, as the same main product ions are consistently observed. Despite major CID pathways of 5 being similar to those previously described for 3, these compounds were apparently more stable and did not suffer imidazolidin-4-one ring disruption under similar conditions [45]. This indicates that insertion of one AA residue between the parent drug and the imidazolidin-4-one scaffold might render the latter slightly less stable towards in-source fragmentations. On the other hand, Structures 6, like their precursors 3, also bear an imidazolidin-4-one ring stable towards collision-induced dissociation, demonstrating that $N$-acylation of the imidazolidin-4-one's N-1 atom with an amino acid does not decrease the ring's stability in the NSR. Interestingly, this correlates with our previous observations regarding the stability of these three families of compounds in aqueous solution at physiological $\mathrm{pH}$ and $T[41,42,53,54]$.

\section{ESI-MS ${ }^{2}$ Analysis at Varying NCE Values}

The experimental setup chosen to carry out ESI-MS ${ }^{2}$ analyses on compound families 5 and $\mathbf{6}$ was identical to that recently described by us for similar studies on the related compounds derived from 3 [45]. The parent drug (PQ, 1) and its $N$-dipeptidyl derivative PQProAla (4.1) were also included in the study, for comparison. As shown by data in (Supplementary Information Table S1), at normalized collision energy (NCE) values of 10 and $20 \%$, the base-peak in $\mathrm{MS}^{2}$ spectra of all compounds assayed was still the quasi-molecular ion $[\mathrm{M}+\mathrm{H}]^{+}$. Fragmentations were only significant at NCE $\geq 30 \%$, and allowed finding relevant differences both between the two series of peptidomimetics (5 and 6) as well as between these, the parent drug (1) and its dipeptide derivative 4.1. As discussed below, 5 and 6 were found to be substantially more stable than both their parent drug (1) and their dipeptide analogue (4.1). Moreover, the distinct behavior of 5 and $\mathbf{6}$ in tandem-MS experiments may serve as a basis for differentiation of isomers in structures bearing imidazolidin-4-one cores.
$M S^{2}$ Fragmentation Pattern of PQAAPro Mimetics (5) at NCE $\geq 30 \%$

At NCE values of $30 \%$ and $40 \%, \mathrm{MS}^{2}$ spectra of all PQAAPro mimetics (5) had their base-peak at $m / z([\mathrm{M}+$ $\mathrm{H}^{+}$)-174, corresponding to fragment 10a (Schemes 2 and 3) formed upon loss of MAQ (7). This behavior reproduces what has been previously observed for imidazolidin-4-one structures like 3, recently reported [45]. Other minor, yet relevant, fragmentations consistently appeared in the $\mathrm{MS}^{2}$ spectra of compounds based on the 5 scaffold at NCE $\geq 30 \%$. Namely, $\mathrm{MS}^{2}$ spectra of such compounds derived from propanone $\left(R^{2}=R^{3}=\right.$ $\mathrm{Me}$ in 5.1 to 5.6) all exhibit a peak whose $m / z$ is compatible with the loss of $75 \mathrm{Da}$, independently of the amino acid side chains $\left(\mathrm{R}^{1}\right.$ and $\left.\mathrm{R}^{4}\right)$ present. Similar observations for compounds derived from cyclohexanone (5.7-5.13) were made, but in this case relevant mass losses were of 18,115 and $147 \mathrm{Da}$. The fact that mass loss values were independent of $R^{1}$ and $R^{4}$ shows that fragmentations must occur at either the 8-AQ ring or the imidazolidin-4-one's C-2, with small fragments being detached and the detected ion still bearing the amino acid side chains intact. As the observed values of $m / z$ were too small to be easily explained by fragmentations exclusively at the 8-AQ level, degradation of the imidazolidin-4-one's ring is proposed (Scheme 3) that provides explanation for both the $m / z$ values detected and their dependency on the nature of the C-2 substituent groups $\left(\mathrm{R}^{2}\right.$ and $\left.\mathrm{R}^{3}\right)$. Thus, loss of $75 \mathrm{Da}$ from Compounds 5.1-5.6 can be explained by concomitant release of methane from the 8-AQ 6-methoxy substituent and isopropylamine from the imidazolidin-4-one ring, with formation of species 14 (Scheme 3). A similar fragmentation occurs for Compounds 5.7-5.13, except that cyclohexylamine is released instead of isopropylamine, which agrees with the loss of 115 instead of $75 \mathrm{Da}$. Further release of two water molecules from 5.7-5.13 leading to 15 would explain the loss of 147 Da. Loss of one of these water molecules before release of methane + alkylamine justifies the occasional observation of peaks corresponding to loss of $18 \mathrm{Da}$ from the parent Structure 5. In the particular case of $\mathbf{5 . 1 4}$ and 5.15, mass losses of $18(\mathrm{~m} / \mathrm{z} 540)$ and $147 \mathrm{Da}(\mathrm{m} / \mathrm{z} 411)$ were observed, consistent with similar dissociation steps, i.e., water elimination followed by concomitant release of methane and 4-methylcyclohexylamine (5.14) or cycloheptylamine (5.15) to produce 16 (Scheme 3). Globally, the $\mathrm{MS}^{2}$ fragmentation behavior of Structures 5 at NCE $\geq 30 \%$ obeys to a general common pattern, with detachment of MAQ as the main fragmentation pathway. The elimination of MAQ (7) agrees with both our previous work [45] and the reported LC/ESI-MS characterization of PQ (1) and its major contaminant quinocide, carried out by Brondz et al. [36]. Other relevant fragmentations were essentially based on concomitant and/or sequential loss of small molecules such as methane, water and alkylamines, involving opening of the imidazolidin-4-one ring while keeping 


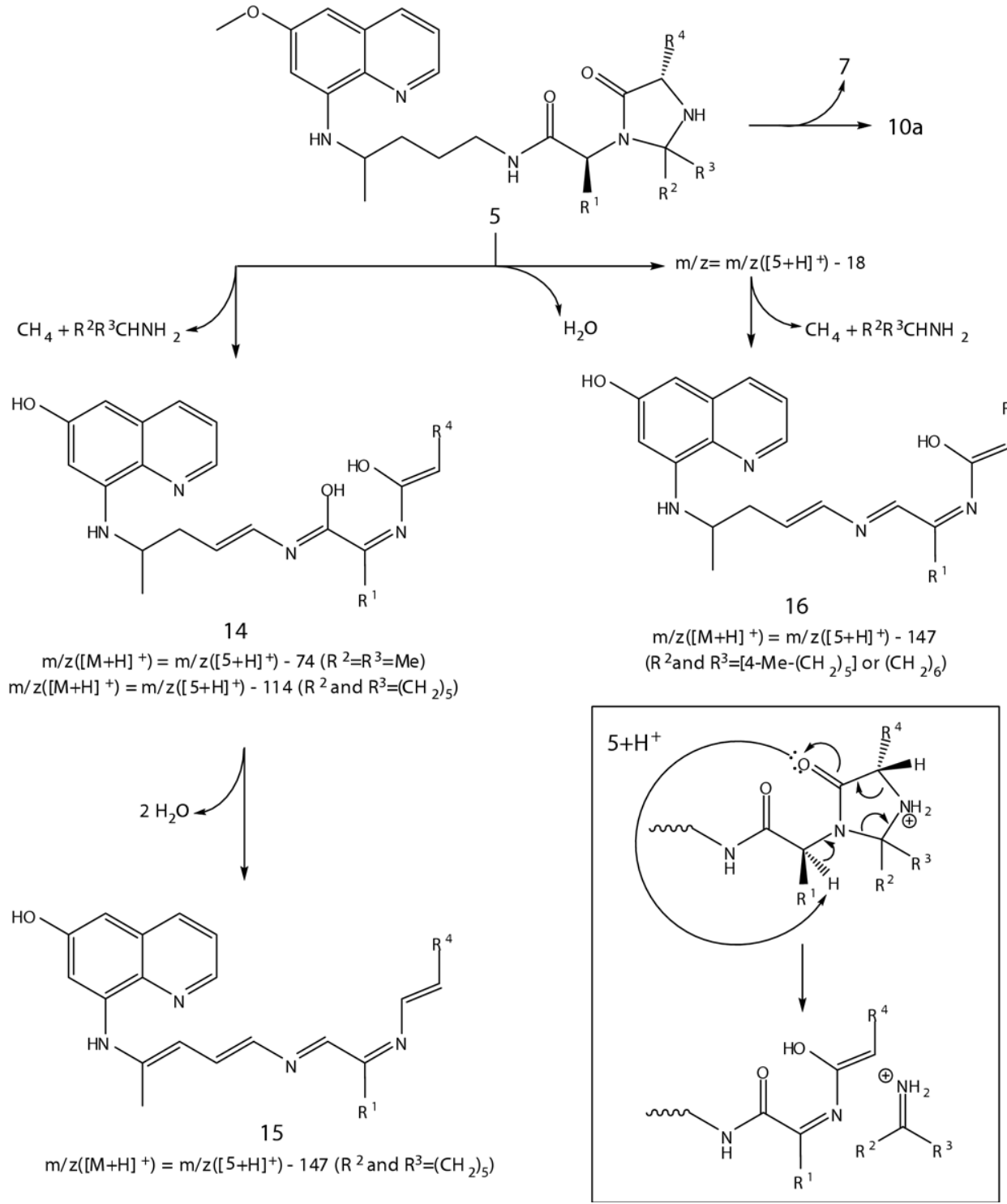

Scheme 3. Proposed fragmentations of Compounds 5, according to peaks consistently observed in $\mathrm{MS}^{2}$ spectra at NCE $\geq 30 \%$. The insert depicts the assumed protonation site of $\mathbf{5}$ to yield the quasi-molecular ion $\mathbf{5}+\mathrm{H}^{+}$that suffers the subsequent charge-driven disruption of the imidazolidin4-one ring (see text).

the quinoline ring intact. As illustrated on the insert in Scheme 3 , we believe the ring opening to be a chargedriven process, as a result of the initial protonation of Structures 5 at the imidazolidin-4-one's N-1 atom.

These findings are in overall agreement with previous findings by Smyth and coworkers, in the course of ESI-MS $^{n}$ studies of selected drugs [6, 26-28].

\section{$M S^{2}$ Fragmentation Pattern of PQProAA Mimetics (6) at NCE $\geq 30 \%$}

$\mathrm{MS}^{2}$ fragmentations of PQProAA mimetics (6), though sharing release of MAQ (7) and/or of "desamino"-PQ (8) with their isomers 5, presented unique characteristics. Explicitly, $\mathrm{MS}^{2}$ spectra obtained at NCE $=30 \%$ for all Structures 6, except that where $R^{1}=R^{4}=H(6.1)$, presented the base-peak at $\mathrm{m} / \mathrm{z} 300$, an observation exclusively made for these compounds (relevant spectra in Supporting Information). In some cases, the difference in intensity between this and the peak due to 10b formed by loss of MAQ (Schemes 2 and 4) was minimal, whereas at NCE $=40 \%$ the base-peak was usually that at $m / z$ 243, assigned to 8 (Figure 2). Additionally, some minor peaks were consistently observed for all Compounds 6.1-6.9, namely, a peak at $m / z 215$ and another due to loss of $75 \mathrm{Da}$ from the original compounds derived from 6 .

Scheme 4 illustrates the pathways proposed to explain the observations exclusive for $\mathrm{MS}^{2}$ spectra of PQProAA mimetics 6. First, the transient formation of the iminium intermediate $\mathbf{1 7}$ can justify the formation of ion 18 whose $\mathrm{m} / \mathrm{z}$ is 300 . This species could be produced 


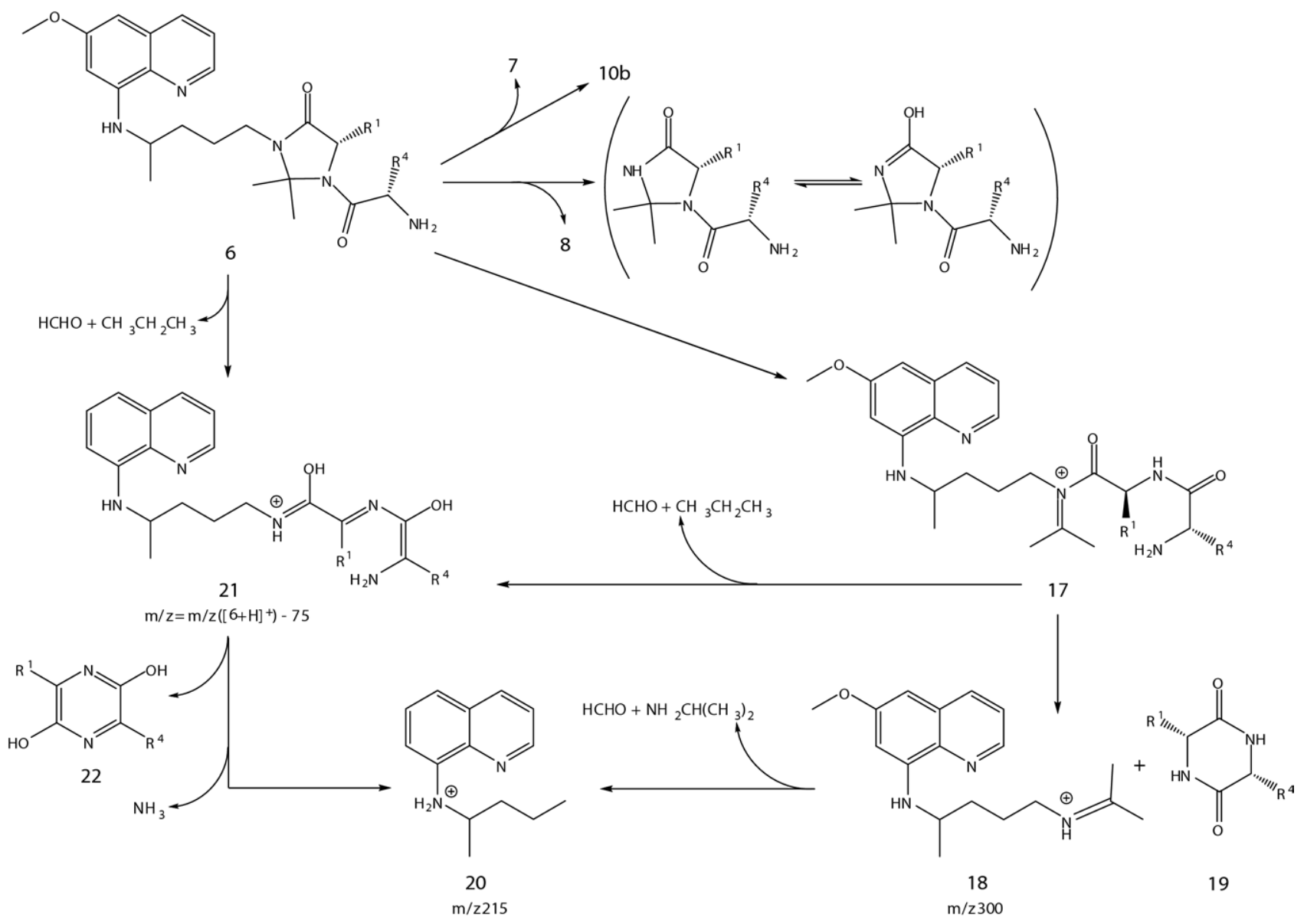

Scheme 4. Fragmentation routes for 6, according to peaks steadily observed in ESI-MS ${ }^{2}$ at NCE $\geq 30 \%$.

through a spontaneous cyclization-elimination reaction of 19, with concomitant release of a neutral 2,5-diketopiperazine (DKP, 19), a mechanism that is parallel to what has been described for tandem-MS fragmentations of oligopeptides [9-17]. In the so-called "diketopiperazine pathway", first reported by Cordero et al. [9] and then thoroughly explored by Paisz and Suhai [10-13], the oligopeptide is described to undergo $\mathrm{O}$-protonation of its $\mathrm{N}$-terminal amide carbonyl, after which proton transfer to the amide nitrogen and cis-
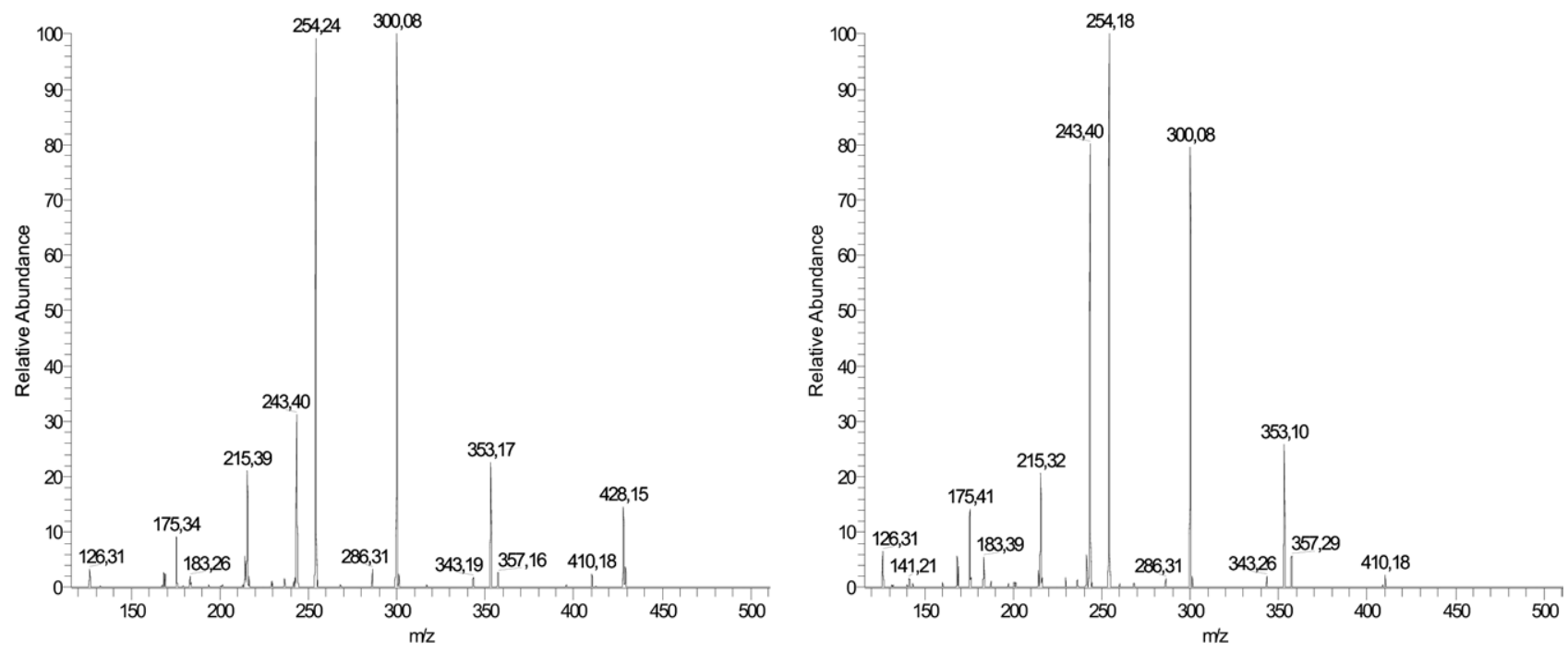

Figure 2. MS ${ }^{2}$ spectra of 6.2 at NCE 30\% (left) and 40\% (right) (expanded between $\mathrm{m} / \mathrm{z} 100$ and 500). 
trans isomerization of the amide bond occur before intramolecular attack of the $N$-terminal primary amine to the $N$-terminal amide carbonyl. As cis-trans isomerization step is a requirement of the "diketopiperazine pathway", this is expectedly more favored in oligopeptides where the $N$-terminal AA is directly linked to Gly, Sar, or, especially, Pro as the second AA in the sequence $[10-13,62]$. Indeed, the gas-phase structure of a Procontaining $b_{2}$ ion was recently confirmed to be a DKP [14] and it is reasonable to expect that a similar fragmentation pathway can occur on peptidomimetic structures as $\mathbf{6}$ that bear Pro-like building blocks. In the particular case of these compounds, they must be first protonated at the imidazolidin-4-one's N-1 atom, which leads to ring opening by disruption of the C-2-N-2 bond, yielding the iminium ion 17. This ion can be regarded as a $C$-terminally modified tripeptide mimetic that, by virtue of its origin from the imidazolidin-4-one 6, is most probably already adopting the correct conformation for the cyclization-elimination reaction to readily take place, producing both the neutral DKP and ion $\mathbf{1 8 .}$

Additional support to the above hypothesis comes from the fact that $\mathbf{1 8}$ can be further degraded by loss of small molecules such as formaldehyde and isopropylamine, leading to formation of $\mathrm{N}$-(2-pentyl)quinolin8 -amine (20) at $\mathrm{m} / \mathrm{z} 215$ (Scheme 4). Moreover, both the iminium intermediate $\mathbf{1 7}$ and the original Compound 6 can lose formaldehyde and propane to give species 21 that has less $75 \mathrm{Da}$ than the original Compound $\mathbf{6}$. Formation of $\mathbf{2 1}$ explains the consistent observation of peaks due to a constant mass loss of 75 Da from Structures 6, independent of the nature of both $\mathrm{R}^{1}$ and $\mathrm{R}^{4}$. Species 21 could eventually also undergo a cyclization-elimination reaction to release neutral 2,5-dihydroxypyrazines 22 , further contributing to formation of $\mathbf{2 0}(\mathrm{m} / \mathrm{z} 215)$ through additional loss of ammonia (Scheme 4 ).

$\mathrm{MS}^{2}$ fragmentation of $\mathbf{6}$ involving formation of $\mathbf{1 8}$ is further supported by the regular observation of minor peaks at $m / z 286$ (for 6.1, 6.2, 6.7, 6.8) and at $m / z 256$ (6.4, $6.5,6.6,6.9)$, assigned to loss of methane and isopropane, respectively, from 18. Finally, the fragmentation pathway proposed in Scheme 4 is reinforced by $\mathrm{MS}^{3}$ fragmentations focused on the ion isolated at $m / z 300$, as discussed in an earlier section.

Overall, routes proposed in Scheme 4 do not only explain key peaks in $\mathrm{MS}^{2}$ spectra of peptidomimetics 6 at $\mathrm{NCE} \geq 30 \%$, but also justify why many of those peaks are exclusive of these compounds, not being detected on similar experiments with either their isomers 5 or their precursors 3 . It could be argued that formation of 21 is parallel to some dissociation steps proposed for type 5 structures (Scheme 3), i.e., imidazolidin-4-one ring opening with expulsion of C-2 and its substituent groups. However, in PQProAA mimetics 6, the imidazolidin-4one's N-1 has to remain attached to the major fragment detected, otherwise mass losses higher than $75 \mathrm{Da}$ had to be detected. The different behavior of 5 and 6 regarding ring opening suggests that $\mathrm{BDE}(\mathrm{C}-2-\mathrm{N}-1)$ in $6>\mathrm{BDE}(\mathrm{C}-2-\mathrm{N}-1)$ in $\mathbf{5}$, which is consistent with the fact that $\mathrm{N}-1$ is part of a tertiary amide in the former, whereas it is a secondary amine in the latter.

\section{Fragmentation Patterns of the Parent Drug, 1, and} of the Imidazolidinone Mimetic $\mathbf{4 . 1}$

As mentioned before, the behavior of both 4.1 (PQProAla), the dipeptide derivative mimicked by $\mathbf{6 . 2}$ and 1, the parent drug was also studied under identical conditions (Table S1 and spectra in Supplementary Information). $\mathrm{MS}^{2}$ fragmentations of PQ (1) were limited to loss of ammonia to yield $\mathbf{8}$ and its further degradation into MAQ (7). Relevantly, MS ${ }^{2}$ degradations of both 1 and 4.1 were already detected at NCE $20 \%$ and at NCE $30 \%$, relative abundances of MAQ (7) were much lower for imidazolidin-4-ones 5 and 6 than for 1 and 4.1, which had completely disappeared at that NCE value (Table S1). Fragmentations of $\mathbf{4 . 1}$ included dehydration $(\mathrm{m} / \mathrm{z}$ $410)$, release of PQ $(m / z 260)$, and its further fragmentation into $8(\mathrm{~m} / \mathrm{z} 243)$ and into $7(\mathrm{~m} / \mathrm{z}$ 175). Interestingly, release of PQ from Compounds 5 or $\mathbf{6}$ was not significant under identical conditions, which provides grounds to conclude that use of pseudo-proline dipeptide carriers such as in 5 or 6 renders the PQ-carrier bond much stronger.

The effect of replacing Pro by its imidazolidin-4-one surrogate in 6 on the detachment of the AA condensed to the pentagonal ring was also analyzed. This was a minor $\mathrm{MS}^{2}$ fragmentation for both 4.1 and 6 that led to release of PQPro and Structures 3, respectively. A ranking of the relative intensities of peaks corresponding to the relevant fragments could be established (Figure 3), allowing to observe that Ala is more promptly released from 4.1 than from its analogue 6.2, and also that the ease of release of the amino acid directly linked to the imidazolidin-4-one N-1 depends on the nature of that same amino acid, as detachment of those bearing larger, $\beta$-branched, $\mathrm{R}^{4}$ side chains (6.3, 6.5) occurs at higher extension. Interestingly, Compounds 6 that are more prone to release the amino acid coupled to the imidazolidin-4-one's N-1 are those with a lower ability to release MAQ (Table S1, Figure 3), which explains why $\mathbf{1 0 b}$ is the most abundant $\mathrm{MS}^{2}$ product ion only for $6.1\left(\mathrm{R}^{4}=\mathrm{H}\right)$.

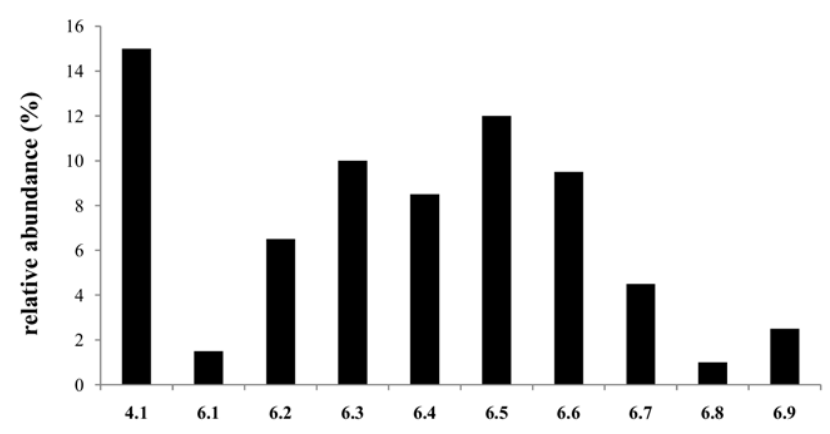

Figure 3. Relative abundance of the species due to loss of the amino acid linked to the pentagonal ring in 4.1 and 6.1-6.9. 


\section{Correlation Between the Relative Abundance of $10 b$ and the Substituent Group $R^{4}$}

From the findings described in the above subsection, the question immediately arose whether the relative abundance of fragment 10b, formed upon loss of MAQ from Compounds $\mathbf{6}$ (Schemes $\mathbf{2}$ and 4), could be correlated with the size of the amino acid's side chain $\mathrm{R}^{4}$. Therefore, we selected the subset of Compounds 6.2, 6.3, 6.4, 6.5, 6.7 that shared glycine as the first amino acid residue $\left(\mathrm{R}^{1}=\mathrm{H}\right)$ and contained different amino acids attached to the imidazolidin-4-one's $N-1$, so that the respective side chains $\left(R^{4}\right)$ were associated to different values of the Charton's steric parameter, $\nu$ [63]. The $\log$ of the relative abundances of species $10 \mathrm{~b}$ generated from that subset of compounds was then represented against the value of $\nu$ associated to each $\mathrm{R}^{4}$ (Supplementary Information Table S2) resulting in the perfect linear correlation shown on Figure 4. As far as we know, this is the first time that tandem-MS fragmentation patterns have been correlated with purely steric factors.

The negative slope obtained indicates that steric crowding imposed by the amino acid's side-chain $\mathrm{R}^{4}$ partially inhibits or delays the formation of $10 \mathrm{~b}$, thus rendering the parent Compounds 6 more stable under the fragmentative conditions employed. In contrast, no correlation with the electronic Taft $\sigma^{*}$ parameter [63] was found. Possibly Compounds 6 adopt a folded conformation in the gas phase, with voluminous $\mathrm{R}^{4}$ groups exerting some kind of shielding effect over the bond that is broken to yield 10b. Folded conformations in the gas phase have been previously obtained in geometry optimization studies focused on the precursor Compounds 3 [43], which gives support to the above hypothesis.

\section{ESI-MS ${ }^{n}$ Analysis at NCE $=30 \%$}

As described in the previous section, fragmentations occur on peptidomimetics $\mathbf{5}$ and $\mathbf{6}$ only at 30\% and higher NCE values. Thus, to carry out a full study of the fragmentation mechanisms of those PQ-derived imidazolidin4-ones, we have fixed the NCE at $30 \%$ and performed an extended $\mathrm{MS}^{n}$ analysis, following the experimental

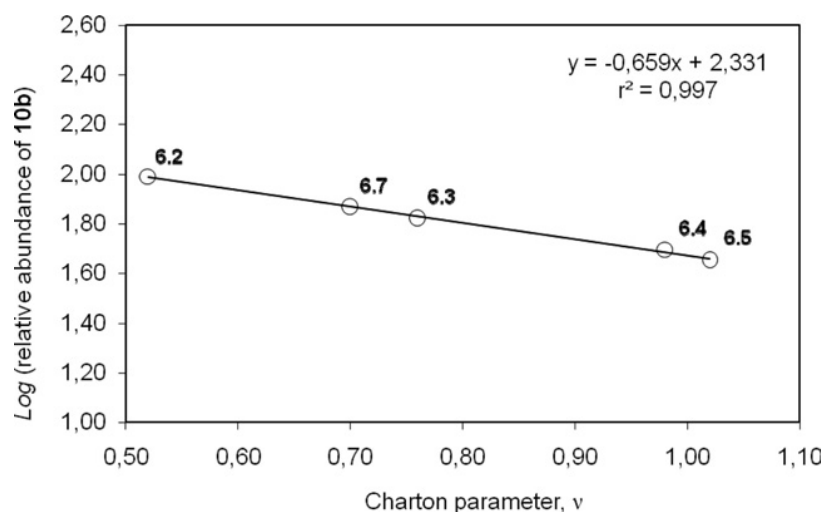

Figure 4. Plot of $\log$ (relative abundance of $\mathbf{1 0 b}$ ) versus the Charton's steric parameter, $v$, associated to the amino acid's side-chain $\mathrm{R}^{4}$. setup given in an earlier section. $\mathrm{MS}^{2}$ analysis at $\mathrm{NCE}=30 \%$ has been covered in the previous section and will be no further discussed, except in what concerns eventual inputs from $\mathrm{MS}^{3}$ and /or MS ${ }^{4}$ data that may help to shed some additional light on the $\mathrm{MS}^{2}$ fragmentation pathways above proposed.

Selection of fragments due to loss of MAQ for further $\mathrm{MS}^{n}$ studies of the title compounds led to $\mathrm{MS}^{3}$ and $\mathrm{MS}^{4}$ spectra that were globally similar for both families of the peptidomimetic derivatives of PQ. As discussed below, these spectra were consistent with fragmentations involving release of small molecules, including amines and carbon monoxide. Further support to formation of $\mathbf{1 8}$ from 6, as proposed in Scheme 4, was provided by additional fragmentations of the ion isolated at $m / z 300$.

\section{ESI-MS ${ }^{n}$ Study of PQAAPro Mimetics (5)}

Ion 10a (Scheme 2) was selected for $\mathrm{MS}^{n}$ fragmentation studies on PQAAPro mimetics (5). Loss of 85 Da was the main, and often the only, event registered on $\mathrm{MS}^{3}$ spectra of these compounds, so that the $\mathrm{MS}^{3}$-generated fragment with $m / z\left(\left[10 \mathbf{a}+\mathrm{H}^{+}\right)-85\right.$ was selected for further $\mathrm{MS}^{4}$ fragmentations. In these, loss of $28 \mathrm{Da}$ was the most relevant event consistently observed (Supplementary Information Table S3). Scheme 5a illustrates the pathway proposed according to the above findings, showing that loss of $85 \mathrm{Da}$ agrees with release of pent-4-en-1-amine, yielding species 23a from which detachment of carbon monoxide explains a further loss of $28 \mathrm{Da}$ to produce the main species, 24a, observed in $\mathrm{MS}^{4}$ spectra. Data obtained does not allow ruling out the possibility that ethylene $\left(\mathrm{C}_{2} \mathrm{H}_{4}\right)$ instead of $\mathrm{CO}$ is detached from 23a, but the latter molecule is more likely to have been released from the 23a scaffold.

$\mathrm{MS}^{3}$ spectra of most compounds derived from cyclohexanone (5.7-5.13) also showed fragmentation of 10a to $23 \mathbf{a}$ as the main event, but often accompanied by further fragmentation to 24a plus additional loss of 45 $\mathrm{Da}$ from the latter. At first, this could be ascribed to release of propane due to concomitant disruption of the imidazolidin-4-one and the cyclohexane rings, but such would correspond to loss of only $44 \mathrm{Da}$. Therefore, loss of $45 \mathrm{Da}$ was probably due to release of carbon monoxide and ammonia, though it is difficult to explain why this only happened for the cyclohexanone-derived structures. Despite the higher number of relevant fragments observed in $\mathrm{MS}^{3}$ spectra of 5.7-5.13 compared with those of 5.1-5.6, relative abundances of unfragmented 10a remaining after $\mathrm{MS}^{3}$ and $\mathrm{MS}^{4}$ experiments were generally higher for cyclohexanone derivatives. Particularly in the case of 5.14, an additional fragment at $\mathrm{m} / \mathrm{z} 242$ was observed in the $\mathrm{MS}^{3}$ spectrum, representing loss of $57 \mathrm{Da}$ from the corresponding species 23a. This was assigned to release of isobutane with concomitant opening of both the 4-methyl-cyclohexane and imidazolidin-4-one rings. Compound $\mathbf{5 . 1 5}$ also displayed the same general pattern, i.e., the main $\mathrm{MS}^{3}$ 
<smiles>[Z]C1NC([R])([R])N(C([Z])C(=O)NCCCC=C)C1=O</smiles>

10a<smiles>[Z2]C(N)C(=O)N1[C@H]([R1])C(=O)N(CCCC=C)C1(C)C</smiles>

$10 \mathrm{~b}$
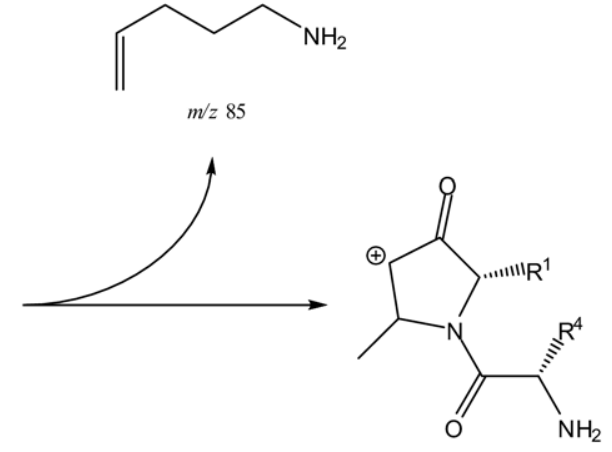

$23 \mathbf{b}$<smiles>[Z7]C1N=C([C@@H](C)NC(C)=O)OC1=O</smiles>

23a
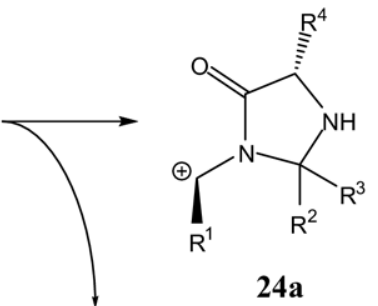

$\mathrm{CO}$<smiles></smiles>

Scheme 5. Main ESI-MS ${ }^{n}(n=3,4)$ disintegrations of Compounds 5 and $\mathbf{6}$ starting from the corresponding $\mathrm{MS}^{2}$-generated fragments 10a (a) and $\mathbf{1 0 b}(\mathbf{b})$, respectively. Major fragmentative events are indicated by full arrows, whereas dashed arrows depict fragmentations particular to a given compound or subset of compounds (see text).

fragmentation was loss of $85 \mathrm{Da}$ from 10a to yield 23a, whose further fragmentation in the $\mathrm{MS}^{4}$ experiment led to the usual loss of $28 \mathrm{Da}$. The second most relevant $\mathrm{MS}^{3}$-generated fragment of $\mathbf{5 . 1 5}$ was formed through loss of $147 \mathrm{Da}$, assigned to opening of the imidazolidin4-one ring to release phenylalanine.

\section{ESI-MS ${ }^{n}$ Study of PQProAA Mimetics (6)}

In what concerns the parallel study focused on PQProAA mimetics 6 or, in better words, on their $\mathrm{MS}^{2}$-derived fragments $10 \mathrm{~b}$ (Scheme 2), loss of $85 \mathrm{Da}$ in the course of $\mathrm{MS}^{3}$ experiments and loss of $28 \mathrm{Da}$ by further $\left(\mathrm{MS}^{4}\right.$ fragmentation of the main $\mathrm{MS}^{3}$ generated species were also the most frequent situation, coherent with the degradation pathway proposed in Scheme 5b. However, exceptions were found for Compounds 6.4, 6.5, 6.6, and 6.8. In the first two cases, the only difference was that no species were detected in their $\mathrm{MS}^{4}$ spectra, which was attributed to the fact that the fragments eventually produced should have $m / z<50$, as this is the lower limit of detection of the ESI-IT MS spectrometer used. In what concerns 6.6, the main $\mathrm{MS}^{3}$-generated fragment arose from loss of $58 \mathrm{Da}$, and its subsequent $\mathrm{MS}^{4}$ fragmentation caused further loss of $85 \mathrm{Da}$. The same 
phenomena occurred for 6.8, but in the opposite order, as the main species registered on the $\mathrm{MS}^{3}$ spectrum arose from loss of $85 \mathrm{Da}$ and the ensuing $\mathrm{MS}^{4}$ fragmentation led to loss of $58 \mathrm{Da}$. These obser- vations were interpreted as sequential release of butane and $N$-isopropyl- $N$-vinylamine, and vice versa, as depicted on Scheme $\mathbf{5 b}$ steps B1 and B2. The 58-Da loss could be also due to acetone rather than
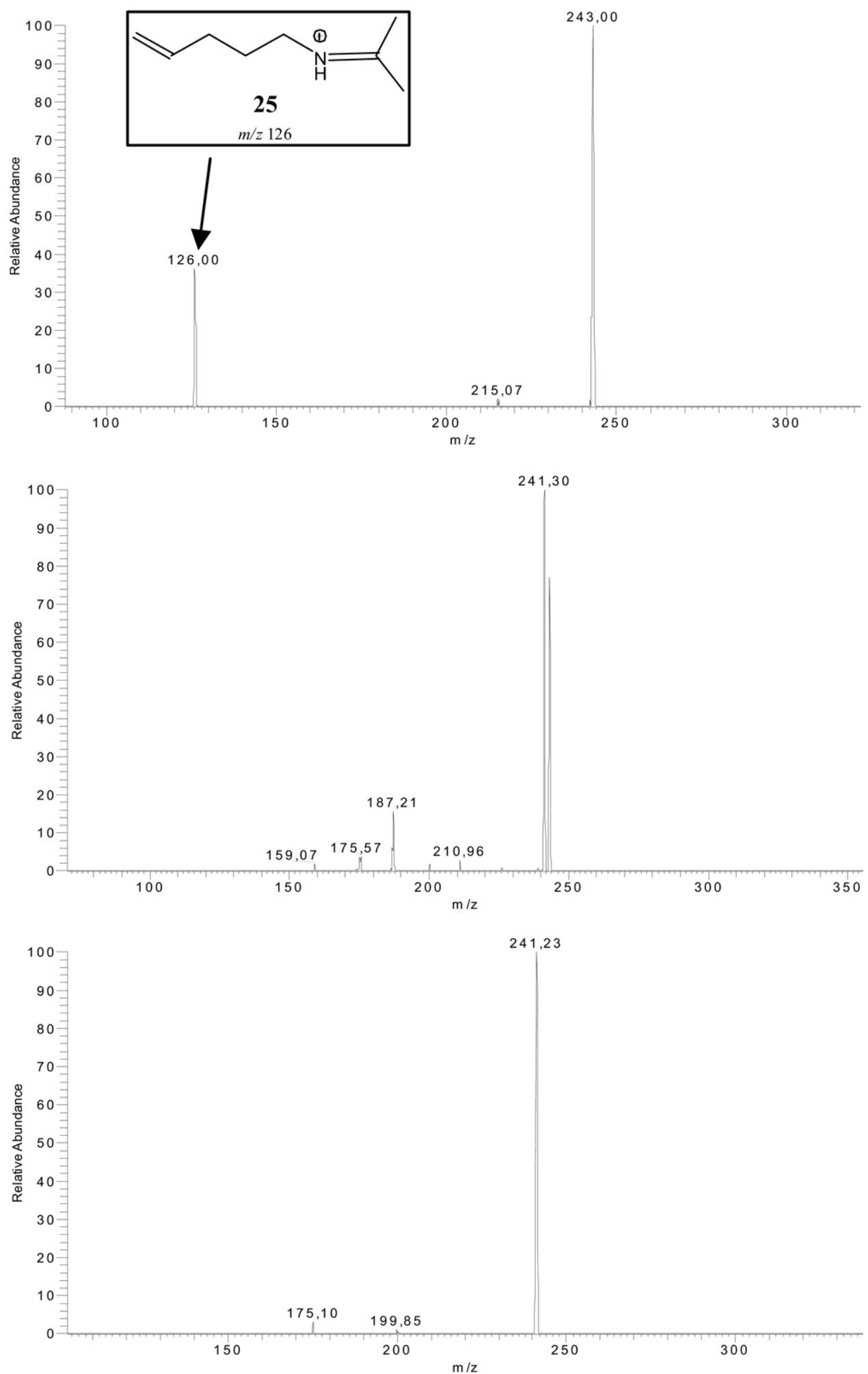

Figure 5. $\mathrm{MS}^{3}, \mathrm{MS}^{4}$, and $\mathrm{MS}^{5}$ (top to bottom) fragmentations of the ion detected at $\mathrm{m} / \mathrm{z} 300$ in $\mathrm{MS}^{2}$ spectra of 6 (illustrated for 6.2). 
butane release, but there is not enough experimental evidence to provide a definitive answer.

Still in connection with the fragmentation studies of Compounds 6, additional ESI-MS ${ }^{n}$ experiments were conducted to shed additional light on the structural identification of the fragment detected at $m / z 300$ in the $\mathrm{MS}^{2}$ spectra of all Compounds 6 . The structure of such fragment was proposed to be $\mathbf{1 8}$ (Scheme 4) and its further fragmentation in the course of ESI-MS ${ }^{n}$ experiments at NCE 30\% provided additional support to this hypothesis, as it consistently led to formation of $\mathbf{8}$ together with another fragment at $\mathrm{m} / \mathrm{z} 126$ that agrees with Structure 25 (Figure 5). Further fragmentations led to decomposition of the aliphatic chain of 8 (Figure 5).

\section{ESI-MS $S^{n}$ Study of the Parent Drug, 1, and the Imidazolidinone Mimetic Compound 4.1}

In what concerns PQ (1), further disintegration of the $\mathrm{MS}^{2}$-generated species $8(\mathrm{~m} / \mathrm{z} 243)$ was virtually impossible, as 8 was still the only species detectable in the $\mathrm{MS}^{3}$ and $\mathrm{MS}^{4}$ spectra of $\mathrm{PQ}$, with the exception of a very minor peak at $m / z 175(\mathrm{MAQ}, 7)$ in the $\mathrm{MS}^{3}$ spectrum. The same occurred for the proline-based analogue 4.1 which, through detachment of the ProAla peptide as a result of $\mathrm{MS}^{2}$ fragmentations, released PQ whose further disintegration in $\mathrm{MS}^{3}$ and $\mathrm{MS}^{4}$ experiments expectedly led to 8 as the major fragment and to 7 as the minor one.

\section{Conclusions}

Two families of peptidomimetic derivatives of $P Q$, bearing the imidazolidin-4-one scaffold as a surrogate of proline, were prepared and characterized by ESI$\mathrm{MS}^{n}$. The fragmentation behaviors of such compounds were markedly different from those of both their parent drug and a dipeptide derivative of the latter, with peptidomimetics being significantly more stable towards ESI-induced dissociation. Moreover, despite sharing some of the major fragmentation routes, the two families displayed relevant differences. Thus, when comparing PQAAPro mimetics (5) with their isomers from the PQProAA series (6), imidazolidin-4-one ring seems more resistant to in-source fragmentation in the latter than in the former. Strikingly, this behavior reflects recent observations regarding compound reactivity towards hydrolysis $[53,54]$. This parallelism between compound reactivity to hydrolysis and stability towards MS fragmentations had already been spotted in the ESI-MS ${ }^{n}$ studies of Compounds 3 [45]. Use of ESI-MS studies as part of investigations on the hydrolysis mechanisms of biodegradable polyesters have been conducted by others [24], showing that ESI-MS can have a role for prediction of compound reactivity towards hydrolysis. Though there is no clear-cut physical explanation for this, as mechanisms in water and in the gas-phase are not comparable, the parallelism is notable and should be object of future reflections.
Tandem-MS analyses allowed establishing a fragmentation pathway exclusive for PQProAA mimetics 6, similar to the "diketopiperazine pathway" described for protonated oligopeptides. This was a key feature to distinguish between both series of peptidomimetics, thus providing a tool for differentiation of imidazolidin-4-one positional isomers. To the best of our knowledge, nothing of this kind was ever reported for imidazolidin-4-one structures. Moreover, an unprecedented structure/ESIreactivity relationship could be drawn for the same series of compounds, as the extension at which a major $\mathrm{MS}^{2}$-fragmentation (loss of MAQ) occurs was seen to be linearly dependent on the size of the AA attached to the imidazolidin-4-one's N-1.

Overall, this study contributes to establish structures like 5 and, especially, 6, as remarkably stable peptidomimetic derivatives of $P Q$, with reported advantages over their precursors 3 [54]. Some of the derivatives 6 have recently been found to display transmissionblocking activities similar to those of the parent drug $\mathrm{PQ}$ and of their precursors 3 [54]. Finally, this work is a valuable contribution towards a deeper insight into the properties of novel structures representing both the 8-AQ and the imidazolidin-4-one classes.

\section{Acknowledgments}

PG and RM thank Foundation for Science and Technology (FCT, Portugal) for support through pluriannual funding to CIQUP and ${ }^{\mathrm{i}}$ Med.UL, respectively. NV thanks FCT for Ph.D. grant SFRH/BD/ $17,754 / 2004$.

\section{References}

1. Smyth, W. F.; McClean, S.; Hack, C. J.; Ramachandran, V. N.; Doherty, B.; Joyce, C.; O'Donnell, F.; Smyth, T. J.; Brooks, P. The Characterization of Synthetic and Natural-Product Pharmaceuticals by Electrospray Ionization-Mass Spectrometry (ESI-MS) and Liquid Chromatography (LC)-ESI-MS. Trends Anal. Chem. 2006, 25, 572-582.

2. O'Donnell, F.; Ramachandran, V. N.; Smyth, W. F.; Hack, C. J.; Patton, H. A Study of the Analytical Behavior of Selected Synthetic and Naturally Occurring Quinolines Using Electrospray Ionization Ion Trap Mass Spectrometry, Liquid Chromatography, and Gas Chromatography, and the Construction of an Appropriate Database for Quinoline Characterization. Anal. Chim. Acta. 2006, 572, 63-76.

3. Smyth, T. J.; Ramachandran, V. N.; McGuigan, A.; Hopps, J.; Smyth, W. F. Characterization of Nicotine and Related Compounds Using Electrospray Ionization with Ion Trap Mass Spectrometry and with Quadrupole Time-of-Flight Mass Spectrometry and Their Detection by Liquid Chromatography/Electrospray Ionization Mass Spectrometry. Rapid Commun. Mass Spectrom. 2007, 21, 557-566.

4. Hofstadler, S. A.; Sannes-Lowery, K. A. Applications of ESI-MS in Drug Discovery: Interrogation of Noncovalent Complexes. Nat. Rev. Drug Discov. 2006, 5, 585-595.

5. Nicolas, O.; Farenc, C.; Calas, M.; Vial, H. J.; Bressole, F. Quantification of Antimalarial Bisthiazolium Compounds and Their Neutral Bioprecursors in Plasma by Liquid Chromatography-Electrospray Mass Spectrometry. Clin. Chem. 2005, 51, 593-602.

6. Smyth, W. F.; Leslie, J. C.; McClean, S.; Hannigan, B.; Mckenna, H. P. Doherty, B.; Joyce, C.; O'Kane, E. The Characterization of Selected Antidepressant Drugs Using Electrospray Ionization with Ion Trap Mass Spectrometry and with Quadrupole Time-of-Flight Mass Spectrometry and Their Determination by High-Performance Liquid Chromatography/Electrospray Ionization Tandem Mass Spectrometry. Rapid Commun. Mass Spectrom. 2006, 20, 1637-1642.

7. Tozuka, Z.; Kaneko, H.; Shiraga, T.; Mitani, Y.; Kawamura, A.; Kagayama, A.; Aoba, A. Strategy for Structure Elucidation of Drug Metabolites Derived from Protonated Molecules and (MS) ${ }^{n}$ Fragmentation of Zotepine, Tiaramide, and Their Metabolites. Drug Metabol. Pharmacokin. 2002, 4, 316-339.

8. Peng, Z.; Song, W.; Han, F.; Chen, H.; Zhu, M.; Chen, Y. Chromatographic Tandem Mass Spectrometric Detection of Papaverine and Its Major Metabolites in Rat Urine. Int. J. Mass Spectrom. 2007, 266, 114-121. 
9. Cordero, M. M.; Houser, J. J.; Wesdemiotis, C. The Neutral Products Formed during Backbone Fragmentations of Protonated Peptides in Tandem Mass Spectrometry. Anal. Chem. 1993, 65, 1594-1601.

10. Paisz, B.; Suhai, S. Combined Quantum Chemical and RRKM Modeling of the Main Fragmentation Pathways of Protonated GGG. I. Cis-Trans Isomerization Around Protonated Amide Bonds. Rapid Comm. Mass Spectrom. 2001, 15, 2307-2323.

11. Paisz, B.; Suhai, S. Combined Quantum Chemical and RRKM Modeling of the Main Fragmentation Pathways of Protonated GGG. II. Formation of $\mathrm{b}_{1}, \mathrm{y}_{1}$, and $\mathrm{y}_{2}$ Ions. Rapid Comm. Mass Spectrom. 2001, 16, 375-389.

12. Paisz, B.; Suhai, S.; Harrison, A. G. Experimental and Theoretical Investigation of the Main Fragmentation Pathways of Protonated H-Gly-Gly-Sar-OH and H-Gly-Sar-Sar-OH. J. Am. Soc. Mass Spectrom. 2003, 14, 1454-1469.

13. Paisz, B.; Suhai, S. Towards Understanding the Tandem Mass Spectra of Protonated Oligopeptides. 1: Mechanism of Amide Bond Cleavage. J. Am. Soc. Mass Spectrom. 2004, 15, 103-113.

14. Smith, L. L.; Herrmann, K. A.; Wysocki, V. H. Investigation of Gas-Phase Structure of Proline-Containing $b_{2}$ ion. J. Am. Soc. Mass Spectrom. 2006, 17, $20-28$.

15. Laskin, J.; Bailey, T. H.; Futrell, J. H. Mechanisms of Peptide Fragmentation from Time- and Energy-Resolved Surface-Induced Dissociation Studies: Dissociation of Angiotensin Analogs. Int. J. Mass Spectrom. 2007, 249/250, 462-472

16. Ramesh, V.; Nagi Reddy, P.; Srinivas, R.; Srinivasulu, G.; Kunwar, A. C. Differentiation of Three Pairs of Positional Isomers of Hybrid Peptides with Repeats of Phenylalanine b3-h-Valine/b3-h-Valine-Phenylalanine by Electrospray Ionization Tandem Mass Spectrometry. Rapid Commun. Mass Spectrom. 2007, 21, 1401-1408.

17. Balta, B.; Avyente, V.; Lifshitz, C. Elimination of Water from the Carboxyl Group of GlyGlyH ${ }^{+}$. J. Am. Soc. Mass Spectrom. 2003, 14, 1192-1203.

18. Ye, Y.; Cao, L. F.; Niu, M. Y.; Liao, X. C.; Zhao Y. F. ESI-MS Fragmentation Pathways of $N$-Methylpyrrole Polyamide/Peptide Conjugates. Int. I. Mass Spectrom. 2006, 253, 141-145.

19. Li, H.; Yuan, G. Electrospray Ionization Mass Spectral Characteristics and Fragmentation Mechanisms of Angiotensin II and Its Analogues. Int. J. Mass Spectrom. 2006, 252, 54-60.

20. Reddy, P. N.; Ramesh, V.; Srinivas, R.; Sharma, G. V. M.; Nagendar, P.; Subash, V. Differentiation of Some Positional and Diastereomeric Isomers of Boc-Carbo- $\beta^{3}$ Dipeptides Containing Galactose, Xylose, and Mannose Sugars by Electrospray Ionization Tandem Mass Spectrometry (ESI MS/MS). Int. J. Mass Spectrom. 2006, 248, 115-123.

21. Yin, H.; Chacon, A.; Porter, N. A.; Douglas, P.; Masterson, S. Free Radical-Induced Site-Specific Peptide Cleavage in the Gas Phase: LowEnergy Collision-Induced Dissociation in ESI and MALDI Mass Spectrometry. J. Am. Soc. Mass Spectrom. 2007, 18, 807-816.

22. Furtado, N. A. J. C.; Vessecchi, R.; Tomaz, J. C.; Galembeck, S. E.; Bastos, J. K.; Lopes, N. P.; Crotti, A. E. M. Fragmentation of Diketopiperazines from Aspergillus fumigatus by Electrospray Ionization Tandem Mass Spectrometry (ESI-MS/MS). J. Mass Spectrom. 2007, 42, 1279-1286.

23. Reddy, P. N.; Srinivas, R.; Kumar, M. R.; Sharma, G. V. M.; Jadhav, V. B. Boc-Protected Peptides Containing Repeats of L-Ala- $\gamma^{4} \mathrm{Caa} / \gamma^{4} \mathrm{Caa}-\mathrm{L}-$ Ala: Differentiation of Some Positional Isomeric Peptides. J. Am. Soc. Mass Spectrom. 2007, 18, 651-662.

24. Osaka, I.; Watanabe, M.; Takama, M.; Murakami, M.; Arakawa, R Characterization of Linear and Cyclic Polylactic Acids and Their Solvolysis Products by Electrospray Ionization Mass Spectrometry. J. Mass Spectrom. 2006, 41, 1369-1377.

25. McClean, S.; Robinson, R. C.; Shaw, C.; Smyth, W. F. Characterization and Determination of Indole Alkaloids in Frog Skin Secretions by Electrospray Ionization Ion Trap Mass Spectrometry. Rapid Commun. Mass Spectrom. 2002, 16, 346.-354.

26. Joyce, C.; Smyth, F.; Ramachandran, V. N.; O'Kane, E.; Coulter, D. J. The Characterization of Selected Drugs Amine-Containing Side Chains Using Electrospray Ionization and Ion Trap Mass Spectrometry and Their Determination by HPLC-ESI-MS. J. Pharm. Biomed. Anal. 2004, 36, 465-476.

27. Smyth, W. F.; Joyce, C.; Ramachandran, V. N.; O'Kane, E.; Coulter, D. J. Characterization of Selected Hypnotic Drugs and Their Metabolites Using Electrospray Ionization with Ion Trap Mass Spectrometry and with Quadrupole Time-of-Flight Mass Spectrometry and Their Determination by Liquid Chromatography-Electrospray Ionization-Ion Trap Mass Spectrometry. Anal. Chim. Acta. 2004, 506, 203-214.

28. Smyth, W. F. Recent Studies on the Electrospray Ionization Mass Spectrometric Behavior of Selected Nitrogen-Containing Drug Molecules and Its Applications to Drug Analysis Using Liquid ChromatographyElectrospray Ionization Mass Spectrometry. J. Chromatogr. B 2005, 824, $1-20$.

29. Dua, V. K.; Sinha, S. N.; Sharma, V. P. Chromatographic Studies on the Isolation of Peroxydisulphate Oxidation products of primaquine. J. Chromatogr. B 1998, 708, 316-320.

30. Dwivedi, A. K.; Singh, S. S. HPLC and HPTLC Assays for the Antimalarial Agents Chloroquine, Primaquine, and Bulaquine. J. Pharm. Biomed. Anal. 2003, 33, 851-858.

31. Lal, J.; Mehrotra, N.; Gupta, C. R. Analysis and Pharmacokinetics of Bulaquine and Its Major Metabolite Primaquine in Rabbits Using an LC-UV Method-a Pilot Study. J. Pharm. Biomed. Anal. 2003, 32, 141.

32. Sinha, S. N.; Dua, V. K. Fast Atom Bombardment Mass Spectral Analysis of Three New Oxidative Products of Primaquine. Int. J. Mass Spectrom. 2004, 232, 151-163.
33. Bortocan, R.; Bonato P. S. Enantioselective Analysis of Primaquine and Its Metabolite Carboxyprimaquine by Capillary Electrophoresis. Electrophoresis 2004, 25, 2848-2853.

34. Zsila, F.; Gedeon, G. Binding of Antiprion Agents to Glycosaminoglycans: Evidence from Electronic Absorption and Circular Dichroism Spectroscopy Biochem. Biophys. Res. Commun. 2006, 346, 1267-1274.

35. La-Scalea, M. A.; Menezes, C. M. S.; Matsutami, G. C.: Polli, M. C. Serrano, S. H. P.; Ferreira, E. I. Molecular Modeling of the Voltammetric Oxidation at a Glassy Carbon Electrode of the Antimalarial Drug Primaquine and Its Prodrugs Succinylprimaquine and Maleylprimaquine. Electrochim. Acta. 2006, 51, 5103.

36. Brondz, I.; Ekeberg, D.; Bell, D. S.; Annino, A. R.; Hustad, J. A.; Svendsen, R.; Vlachos, V.; Oakley, P.; Langley, G. J.; Mohini, T.; Amaury, C. G.; Mikhalitsyn, F. Nature of the Main Contaminant in the Drug Primaquine Diphosphate: SFC and SFC-MS Methods of Analysis. J. Pharm. Biomed. Anal. 2007, 43, 937.

37. Avula, B.; Tripathi, L. M.; Khan, S. I.; Tekwani, B. L.; Nanayakkara, D.; Gul, W.; ElSolhly, M. A.; Khan, I. A. LC Method for the Determination of NPC1161, Primaquine, and Their Metabolites in Various Biological Systems. Chromatographia. 2006, 64, 429.

38. Brondz, I.; Mantzilas, D.; Klein, U.; Ekeberg, D.; Hvattum, E.; Lebedeva, M. N.; Mikhailitsyn, F. S.; Souleimanov, G. D.; Roe, J. Nature of the Main Containing in the Antimalaria Drug Primaquine Diphosphate: A Qualitative Isomer Analysis. J. Chromatogr. B 2004, 800, 211-223.

39. Dongre, V. G.; Karmuse, P. P.; Nimbalkar, M. M.; Singh, D.; Kumar, A. Applications of GC-EI-MS for the Identification and Investigation of Positional Isomer in Primaquine, an Antimalarial Drug. J. Pharm. Biomed. Anal. 2005, 39, 111-116.

40. Gomes, P.; Araújo, M. J.; Rodrigues, M.; Vale, N.; Azevedo, Z.; Iley, J.; Chambel, P.; Morais, J.; Moreira, R. Synthesis of Imidazolidin-4-One and $1 \mathrm{H}$-Imidazo[2,1-a] Iisoindole-2,5-(3H,9bH)-Dione Derivatives of Primaquine: Scope and Llimitations. Tetrahedron. 2004, 60, 5551-5562.

41. Araújo, M. J.; Bom, J.; Capela, R.; Casimiro, C.; Chambel, P.; Gomes, P. Iley, J.; Lopes, F.; Morais, J.; Moreira, R.; Oliveira, E.; do Rosário, V. Vale, N. Imidazolidin-4-One Derivatives of Primaquine as Novel Transmission-Blocking Antimalarials. J. Med. Chem. 2005, 48, 888892.

42. Chambel, P.; Capela, R.; Lopes, F.; Iley, J.; Morais, J.; Gouveia, L. Gomes, J. R. B.; Gomes, P.; Moreira, R. Reactivity of Imidazolidin-4-One Derivatives of Primaquine: Implications for Prodrug Design. Tetrahedron 2006, 62, 9883-9891.

43. Ferraz, R.; Gomes, J. R. B.; Oliveira, E.; Moreira, R.; Gomes, P. Unanticipated Stereoselectivity in the Reaction of Primaquine $\alpha$-Aminoamides with Substituted Benzaldehydes: A Computational and Experimental Study. J. Org. Chem. 2007, 72, 4189-4197.

44. Vale, N.; Collins, M. S.; Gut, J.; Ferraz, R.; Rosenthal, P. J.; Cushion, M. T.; Moreira, R.; Gomes, P. Anti-Pneumocystis carinii and Antiplasmodial Activities of Primaquine-Derived Imidazolidin-4-ones. Bioorg. Med. Chem. Lett. 2008, 18, 485-488.

45. Vale, N.; Moreira, R.; Gomes, P. Characterization of Primaquine Imidazolidin-4-Ones with Antimalarial Activity by Electrospray Ionization-Ion Trap Mass Spectrometry. Int. J. Mass Spectrom. 2008, 270, 81-91.

46. Klixbüll, U.; Bundgaard, H. Prodrugs as Drug Delivery Systems XXX. 4-Imidazolidinones as Potential Bioreversible Derivatives for the $\alpha$-Aminoamide Moiety in Peptides. Int. J. Pharm. 1984, 20, 273.

47. Klixbüll, U.; Bundgaard H. Kinetics of Reversible Reactions of Ampicillin with Various Aldehydes and Ketones with Formation of 4-Imidazolidinones. Int. J. Pharm. 1985, 23, 163-173.

48. Rasmussen, G. J.; Bundgaard, H. Prodrugs of Peptides. 10. Protection of Diand Tripeptides Against Aminopeptidase by Formation of BioreversibleImidazolidinones Derivatives. Int. J. Pharm. 1991, 71, 45-53.

49. Rasmussen, G. J.; Bundgaard, H. Prodrugs of Peptides. 15. 4Imidazolidinone Prodrug Derivatives of Enkephalins to Prevent Aminopeptidase-Catalyzed Metabolism in Plasma and Absorptive Mucosae. Int. J. Pharm. 1991, 76, 113-122.

50. Fowles, L. F.; Beck, E.; Worrall, S.; Shanley, B. C.; Jersey, J. The Formation and Stability of Imidazolidinone Adducts from Acetaldehyde and Model Peptides. Biochem. Pharmacol. 1996, 51, 1259-1267.

51. Bak, A.; Fich, M.; Larsen, B. D.; Frokjaer, S.; Früs, G. J. N-Terminal 4-Imidazolidinone Prodrugs of Leu-Enkephalin Synthesis, Chemical, and Enzymatic Stability studies. Eur. J. Pharm. Sci. 1999, 7, 317-323.

52. Larsen, S. W.; Sidenius, M.; Andersen, M.; Larsen, C. Kinetics of Degradation of 4-Imidazolidinone Prodrug Types Obtained from Reacting Prilocaine with Formaldehyde and Acetaldehyde. Eur. J. Pharm. Sci. 2003, 20, 233-240.

53. Vale, N.; Moreira, R.; Gomes, P. Synthesis and Reactivity of Imidazolidin4-Ones of Dipeptide Derivatives of Primaquine: Potential Antimalarial Prodrugs, unpublished.

54. Vale, N.; Matos, J.; Gut, J.; Nogueira, F.; Rosenthal, P. J.; do Rosário, V. Moreira,R.;Gomes,P.Synthesisand AntimalarialActivity ofImidazolidin4-One Peptidomimetic Derivatives of Primaquine. Bioorg. Med. Chem. Lett. 2008, 18, 4150-4153

55. Wöhr, T.; Wahl, F.; Nefzi, A.; Rohwedder, B.; Sato, T.; Sun, X.; Mutter M. Pseudoprolines as a Solubilizing, Structure-Disrupting Protection Technique in Peptide Synthesis. J. Am. Chem. Soc. 1996, 118, 9218-9227.

56. Rinnová, M.; Nefzi, A.; Houghten, R. A. An Efficient Approach for Solid-Phase Synthesis of Peptidomimetics Based on 4-Imidazolidinones. Tetrahedron Lett. 2002, 43, 2343-2346. 
57. Rinnová, M.; Nefzi, A.; Houghten, R. A. Opioid Activity of 4-Imidazolidinone Positional Analogues of Leu-Enkephalin. Bioorg. Med. Chem. Lett. 2002, 12, 3175-3178.

58. Vost, W. Oxidation of Methionyl Residues in Proteins: Tools, Targets, and Reversal. Free Radic. Biol. Med. 1995, 18, 93-105.

59. Sun, H.; Gao, J.; Ferrington, D. A.; Biesiada, H.; Williams, T. D.; Squaier, T. C. Repair of Oxidized Calmodulin by Methionine Sulfoxide Reductase Restores Ability to Activate the Plasma Membrane Ca-ATPase. Biochemistry 1999, 38, 105-112.

60. Moskovitz, J.; Weissbach, H.; Brot, N. Cloning and Expression of a Mammalian Gene Involved in the Reduction of Methionine Sulf- oxide Residues in Proteins. Proc. Natl. Acad. Sci. U.S.A. 1996, 93, 2095-2099.

61. Levine, R. L.; Mosoni, L.; Berlett, B. S.; Stadtman, E. R. Methionine Residues as Endogenous Antioxidants in Proteins. Proc. Natl. Acad. Sci. U.S.A. 1996, 93, 15036-15040

62. Purdie, J. E.; Benoiton, N. L. Piperazinedione Formation from Esters of Dipeptides Containing Glycine, Alanine, and Sarcosine: The Kinetics in Aqueous Solution. J. Chem. Soc. Perkin Trans. 2 1973, 13, 1845-1852.

63. Hansch, C.; Leo, A. Substituent Constants for Correlations Analysis in Chemistry and Biology. Wiley Interscience: New York, 1979; p 527. 